\title{
Autosomal and Z-linked microsatellite markers enhanced for cross-species utility and assessed in a range of birds, including species of conservation concern
}

\author{
Deborah A. Dawson $^{1} \cdot$ Susannah Bird $^{1,2} \cdot$ Gavin J. Horsburgh $^{1} \cdot$ Alexander D. Ball $^{1}$
}

Received: 16 February 2015/Accepted: 15 March 2015/Published online: 15 October 2015

(c) The Author(s) 2015. This article is published with open access at Springerlink.com

\begin{abstract}
Microsatellite markers were designed to be of utility for genotyping multiple species of birds, including those of conservation concern, hence saving resources and enabling species/genome comparisons. We used the proven approach of Dawson et al. (Mol Ecol Resour 10:475-494, 2010) and assessed markers in multiple species, including nine species of conservation interest. We ensured both primer sequences matched multiple species (13 loci) or designed primer sets from expressed sequence tags (2 loci). Eleven primer sets were $100 \%$ identical to the zebra finch (Taeniopygia guttata) and a second passerine species and/ or the chicken (Gallus gallus). All 15 loci were polymorphic when assessed in a non-source species (Gouldian finch, Erythrura gouldiae) suggesting utility in multiple species. Four of the five Z-linked loci were assessed in at least nine additional species each (including ratites). All were variable in multiple species, demonstrating crossspecies utility and potential for identifying $\mathrm{Z}$ chromosome rearrangements.
\end{abstract}

Keywords AVES - Birds · High cross-species utility · Passerine $\cdot$ Simple tandem repeat $(\mathrm{STR}) \cdot \mathrm{Z}$ chromosome

Electronic supplementary material The online version of this article (doi:10.1007/s12686-015-0495-6) contains supplementary material, which is available to authorized users.

Deborah A. Dawson

d.a.dawson@sheffield.ac.uk

1 Department of Animal and Plant Sciences, University of Sheffield, Western Bank, Sheffield S10 2TN, UK

2 Present Address: Department of Biology, University of York, York YO10 5DD, UK

\section{Introduction}

In order to create enhanced microsatellite markers of high cross-species utility we followed the approach of Dawson et al. (2010). We designed primer sets from alignments of multiple species/expressed sequence tags and characterised these in non-source species. Those markers identified as Z-linked based on sequence homology to the zebra finch and genotyping were tested in additional bird species. Z markers with wide cross-species amplification are particularly useful because species-specific allele sizes allow the identification of the parental species of a hybrid individual (e.g. Lifjeld et al. 2010), whereas the more variable $Z$ markers allow the study of cross-species chromosomal rearrangements (e.g. Backström et al. 2006).

\section{Methods}

We followed the approach of Dawson et al. (2010) to enhance the markers for high cross-species utility. We created consensus zebra finch-passerine, zebra finchchicken or zebra finch-passerine-chicken sequences from homologous microsatellite sequences using MEGA3 (for details see Supplementary File 1). Primer sets were designed from these multi-species consensus sequences using PRIMER3 v0.4.0 using a maximum of one degenerate base per primer set.

All markers were assessed in a non-source species, the near-threatened Gouldian finch (Erythrura gouldiae). Since this species was not used in the design of the markers, successful amplification and polymorphism would suggest the marker will be of utility in many species. We tested known sexes to diagnose if the markers were Z-linked or autosomal (Table 1; up to 20 female and 20 male; sexed 


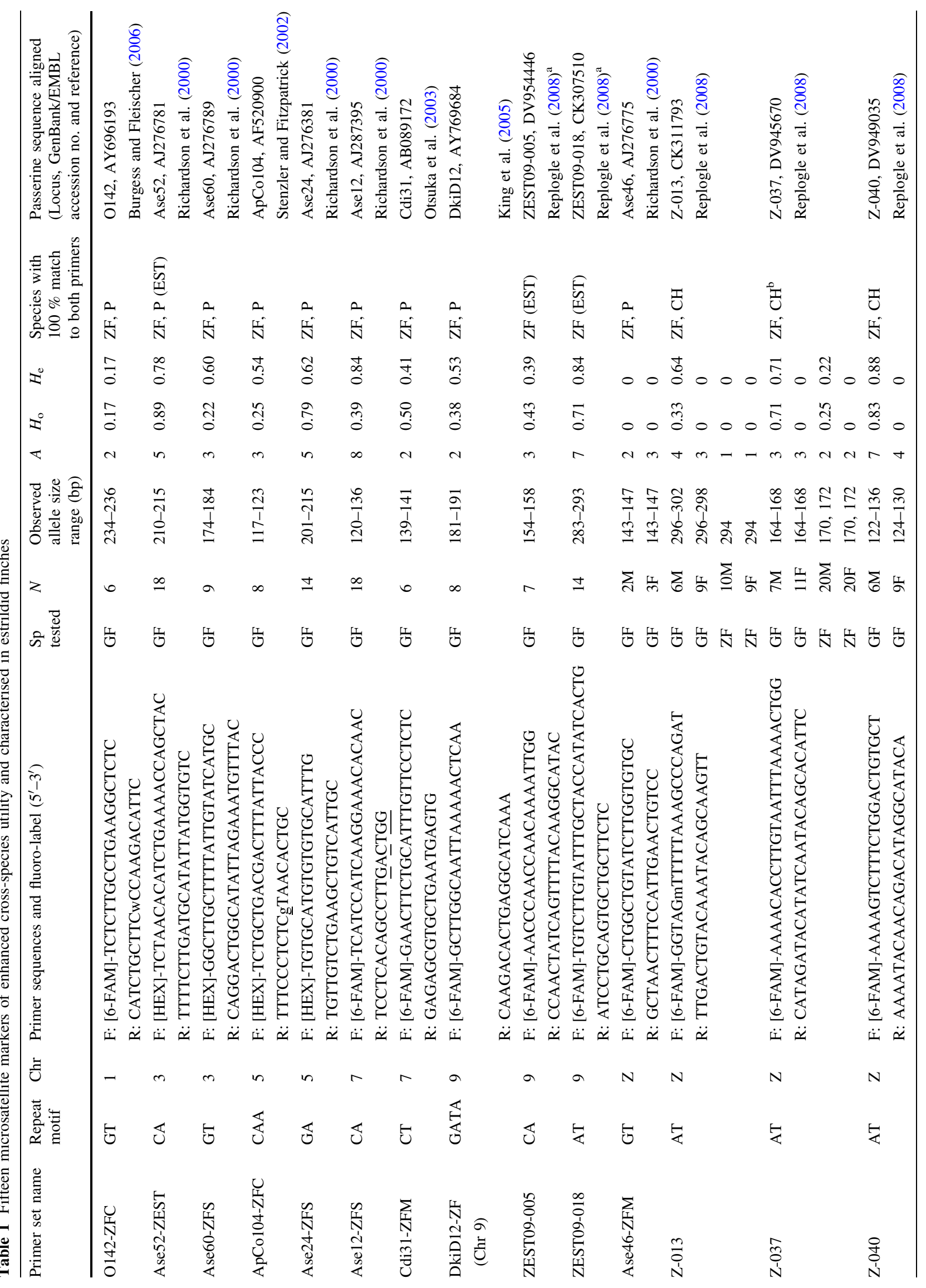




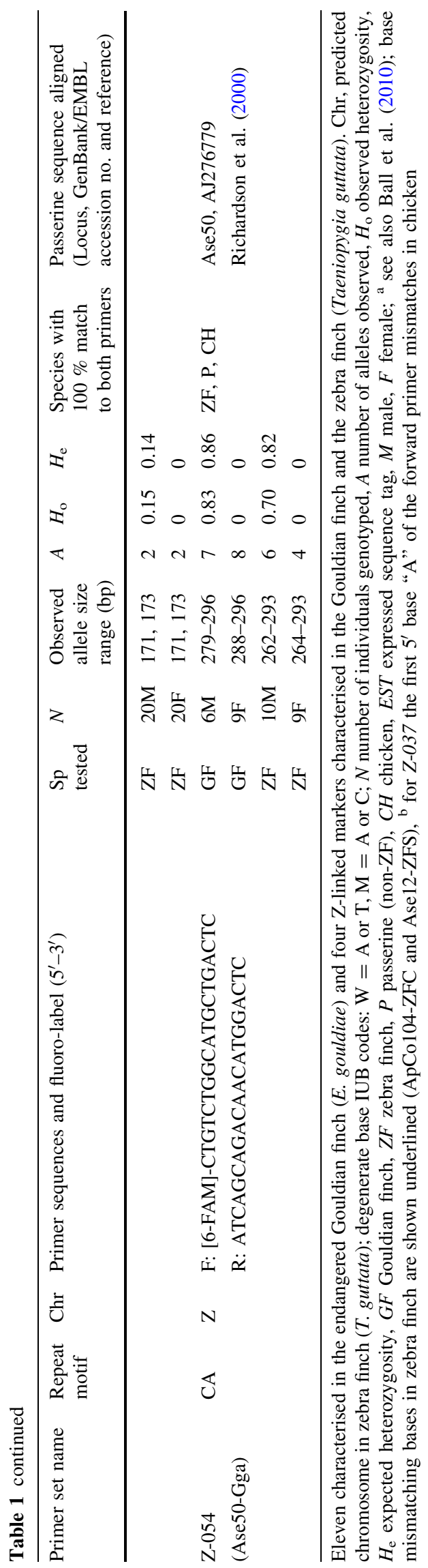

using the marker Z-002A, Dawson 2007). Four of the Z markers were genotyped in 10-23 additional species (including nine species of conservation concern) and the saltwater crocodile Crocodylus porosus (Table 2; 1-40 individuals per species).

Genomic DNA was extracted from blood using an ammonium acetate protocol. Each fluorescent PCR contained approximately $10 \mathrm{ng}$ genomic DNA, in 2- $\mu \mathrm{l}$ volumes using QIAGEN Multiplex PCR Master Mix or 10- $\mu$ l volumes with $2.5 \mathrm{mM} \mathrm{MgCl}_{2}$ and BIOLINE Taq DNA polymerase and buffer. PCR amplification was performed using a DNA Engine Tetrad thermal cycler. PCR amplification conditions were $94{ }^{\circ} \mathrm{C}$ for 15 min (QIAGEN) or $3 \mathrm{~min}$ (Bioline); then 35 cycles of $94{ }^{\circ} \mathrm{C}$ for $30 \mathrm{~s}, 56{ }^{\circ} \mathrm{C}$ for $30 \mathrm{~s}, 72{ }^{\circ} \mathrm{C}$ for $30 \mathrm{~s}$; followed by one cycle of $72{ }^{\circ} \mathrm{C}$ for 10 min. PCR products were loaded on a 48-capillary ABI 3730 DNA Analyzer and genotypes assigned using GeneMapPer software (Applied Biosystems). Heterozygosities were calculated using CERvus and deviation from Hardy-Weinberg equilibrium (HWE) calculated using GENEPOP. Z-linked markers were assessed for HWE when typed in a minimum of 10 individuals and using males only.

\section{Results}

Eleven primer sets were $100 \%$ identical to zebra finch and a second bird species and two sets mismatched at 1-4 bases (ApCo104-ZFC and Ase12-ZFS; Supplementary File 1). Two other sets were designed from zebra finch Expressed Sequence Tags (ESTs) (ZEST09-005 and ZEST09-018; Table 1).

Based on their high multispecies sequence homology and proven utility in multiple non-source species (Table 1, 2), these markers are expected to be of utility for studying many species, including those of conservation concern, especially passerines (see Dawson et al. 2010). Only one locus (Ase12) deviated from HWE, possibly due to null alleles (Table 1). A selection of these markers are being used in parentage studies for multiple species (DAD unpublished data).

For the five loci homologous to the zebra finch $\mathrm{Z}$ chromosome, females were always homozygous (hemizygous), confirming their Z-linked nature in other species, and suggesting no W-linked homologues amplified (Table 1). Four of the Z-linked sequences were highly conserved between genetically distant species (zebra finchchicken; Z-013, Z-037, Z-040 and Ase50) and, as expected, amplified across a wide range of species, including ratites and saltwater crocodile (81-100 \%; Table 2, Supplementary Table 1). These were variable in multiple species demonstrating potential for cross-utility and identifying 


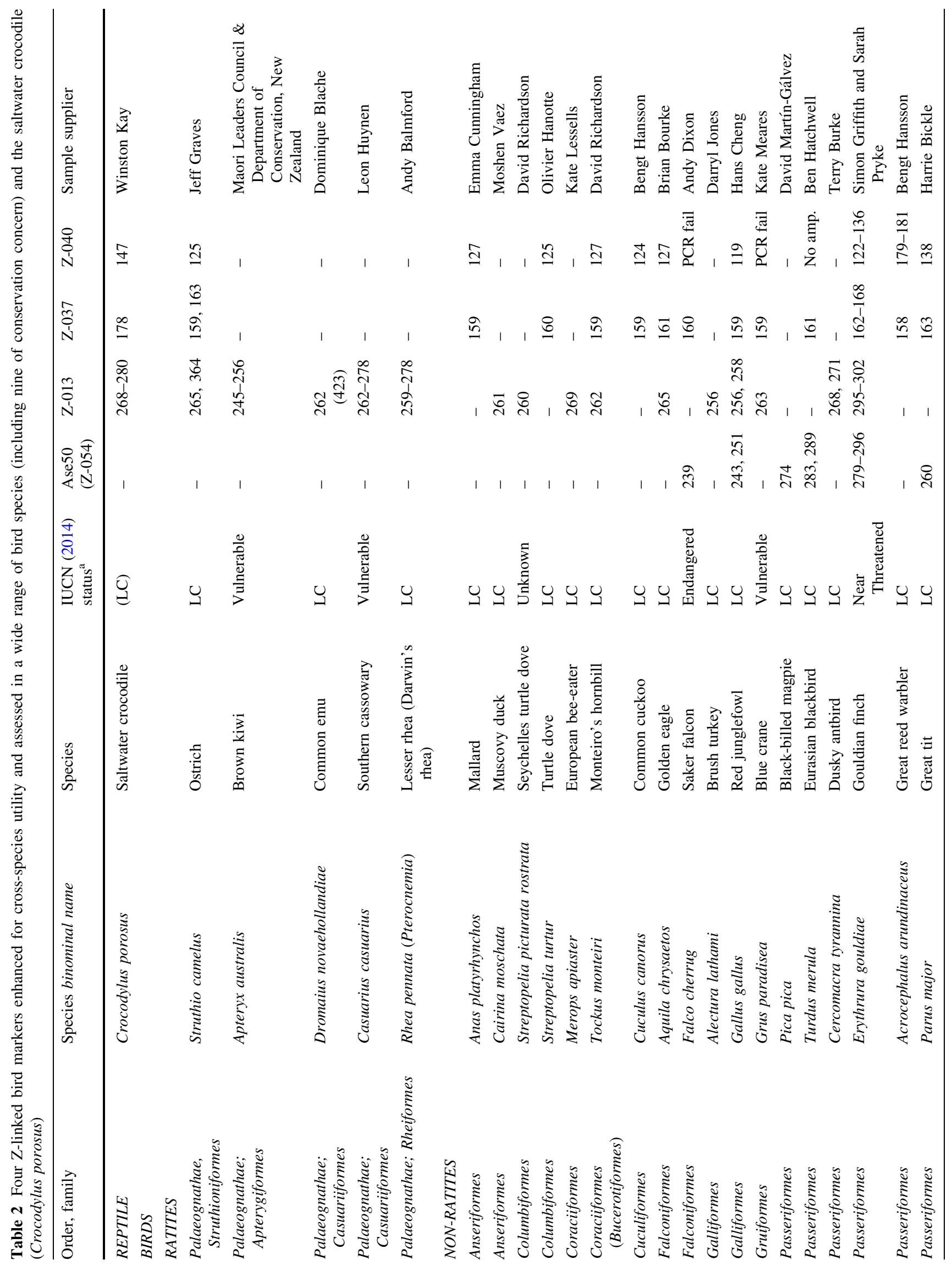




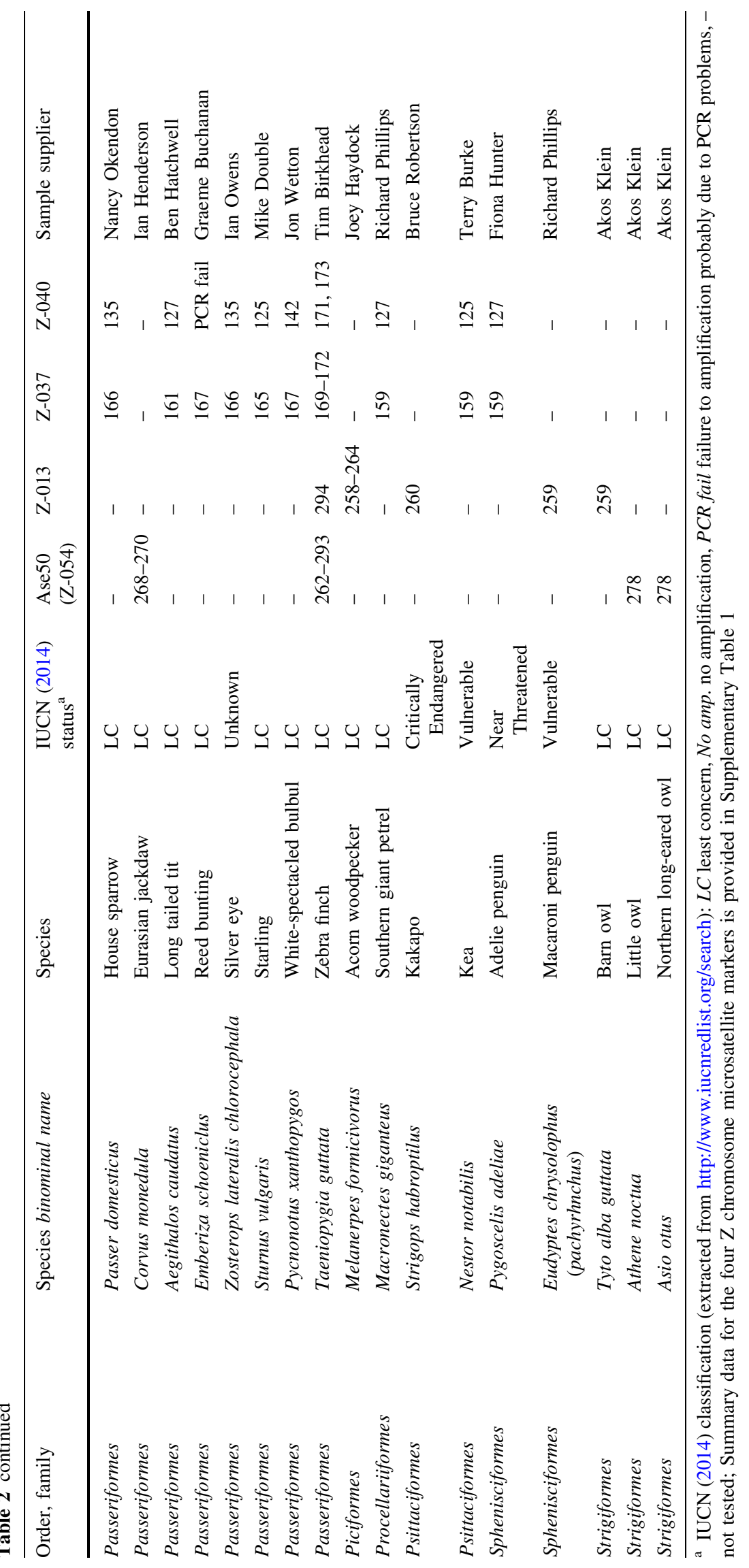


chromosomal rearrangements between species. Allele sizes in some orders were invariant within a species, yet varied in size between species, suggesting potential for identifying species and hybrids (Table 2).

Acknowledgments We thank all those who kindly supplied the samples from various species (identified in Table 2), especially the Maori Leaders Group, the Department of Conservation, New Zealand, Simon Griffith and Sarah Pryke and Tim Birkhead. Kang-Wook Kim provided Gouldian finch genotyping data for two markers. Douglas Ross, Terry Burke and Natalie dos Remedios provided comments on the manuscript. This work was performed at the NERC Biomolecular Analysis Facility at Sheffield supported by the UK Natural Environment Research Council.

Open Access This article is distributed under the terms of the Creative Commons Attribution 4.0 International License (http://crea tivecommons.org/licenses/by/4.0/), which permits unrestricted use, distribution, and reproduction in any medium, provided you give appropriate credit to the original author(s) and the source, provide a link to the Creative Commons license, and indicate if changes were made.

\section{References}

Backström N, Brandström M, Gustafsson L, Qvarnström A, Cheng H, Ellegren H (2006) Genetic mapping in a natural population of collared flycatchers (Ficedula albicollis): conserved synteny but gene order rearrangements on the avian $\mathrm{Z}$ chromosome. Genetics 174:377-386

Ball AD, Stapley J, Dawson DA, Birkhead TR, Burke T, Slate J (2010) A comparison of SNPs and microsatellites as linkage mapping markers: lessons from the zebra finch (Taeniopygia guttata). BMC Genom 11:218

Burgess SL, Fleischer RC (2006) Isolation and characterization of polymorphic microsatellite loci in the Hawaiian flycatcher, the elepaio (Chasiempis sandwichensis). Mol Ecol Notes 6:14-16
Dawson DA (2007) Genomic analysis of passerine birds using conserved microsatellite loci. $\mathrm{PhD}$ Thesis, University of Sheffield, UK

Dawson DA, Horsburgh GJ, Küpper C, Stewart IRK, Ball AD, Durrant KL, Hansson B, Bacon I, Bird S, Klein Á, Lee J-W, Martín-Gálvez D, Simeoni M, Smith G, Spurgin LG, Burke T (2010) New methods to identify conserved microsatellite loci and develop primer sets of high utility - as demonstrated for birds. Mol Ecol Resour 10:475-494

IUCN (International Union for Conservation of Nature and Natural Resources) (2014) The IUCN red list of threatened species. Version 2014.2 (http://www.iucnredlist.org/search) Accessed 9th Oct 2014

King TL, Eackles MS, Henderson AP, Bocetti CI, Currie D, Wunderle JM (2005) Microsatellite DNA markers for delineating population structure and kinship among the endangered Kirtland's warbler (Dendroica kirtlandii). Mol Ecol Notes 5:569-571

Lifjeld JT, Marthinsen G, Myklebust M, Dawson DA, Johnsen A (2010) A wild Marsh Warbler $\times$ Sedge Warbler hybrid (Acrocephalus palustris $\times$ A. schoenobaenus) in Norway documented with molecular markers. J Ornithol 151:513-517

Otsuka R, Nishiumi I, Wada M (2003) Characterization of 12 polymorphic microsatellite loci in the Japanese bush warbler Cettia diphone. Mol Ecol Notes 3:44-46

Replogle K, Arnold AP, Ball GF et al (2008) The Songbird Neurogenomics (SoNG) Initiative: community-based tools and strategies for study of brain gene function and evolution. BMC Genom 9:131

Richardson DS, Jury FL, Dawson DA, Salguiero P, Komdeur J, Burke T (2000) Fifty Seychelles warbler (Acrocephalus sechellensis) microsatellite loci polymorphic in Sylviidae species and their cross-species amplification in other passerine birds. Mol Ecol 9:2226-2231

Stenzler LM, Fitzpatrick JW (2002) Isolation of microsatellite loci in the Florida Scrub-Jay Aphelocoma coerulescens. Mol Ecol Notes 2:547-550 